\title{
The Effects of Combined Physical Exercise on Serum Redox Biomarkers and Leukocyte DNA Damage of Obese Women
}

\author{
Carla Nascimento, ${ }^{1}$ Milena Simões Peixoto, ${ }^{1}$ Luiz Fernando Fonte Boa, ${ }^{1}$ \\ Caroline Coelho de Faria, ${ }^{1}$ Tulio Senna Fonseca Costa, ${ }^{1}$ Leonardo Matta $\left(\mathbb{D},{ }^{1}\right.$ \\ Andrea Claudia Freitas Ferreira, ${ }^{1,2}$ and Rodrigo Soares Fortunato $\mathbb{D}^{1}$ \\ ${ }^{1}$ Instituto de Biofísica Carlos Chagas Filho, Universidade Federal do Rio de Janeiro, Rio de Janeiro, Brazil \\ ${ }^{2}$ NUMPEX, Campus Duque de Caxias, Universidade Federal do Rio de Janeiro, Rio de Janeiro, Brazil \\ Correspondence should be addressed to Rodrigo Soares Fortunato; rodrigof@biof.ufrj.br
}

Received 15 December 2020; Revised 25 February 2021; Accepted 17 March 2021; Published 1 April 2021

Academic Editor: Oluyomi Stephen Adeyemi

Copyright (c) 2021 Carla Nascimento et al. This is an open access article distributed under the Creative Commons Attribution License, which permits unrestricted use, distribution, and reproduction in any medium, provided the original work is properly cited.

\begin{abstract}
Obesity is usually linked to oxidative stress, which can lead to damage to biomolecules. The combination of aerobic and strength exercises seems to induce health benefits in obese individuals, but little is known about the effects of combined physical exercise on redox homeostasis and DNA damage in this population. Thus, the aim of the current study was to determine the effects of 16 weeks of combined physical exercise on biomarkers of oxidative stress and DNA damage in obese women. 17 obese women underwent 16 weeks of a combined physical training program, 3 times per week. Anthropometric and biochemical parameters, serum superoxide dismutase (SOD) and glutathione peroxidase activity, plasma 8-isoprostane levels, and DNA and chromosomal damage were evaluated before and after physical training. Combined physical exercise training decreased body weight $(83.2 \pm 9.6$ vs. $80.2 \pm 9.6 \mathrm{~kg})$, body mass index $\left(33.8 \pm 3.6\right.$ vs. $\left.32.6 \pm 3.7 \mathrm{~kg} \cdot \mathrm{m}^{-2}\right)$, body fat $(40.2 \pm 2.6 \mathrm{vs} .39 .0 \pm 3.2 \%)$, and waist circumference $(99.3 \pm 9.4$ vs. $94.1 \pm 8.8 \mathrm{~cm})$, while the fat-free mass was augmented $(59.9 \pm 2.9 \mathrm{vs} .60 .7 \pm 3.1 \mathrm{~kg})$. Moreover, blood glucose reduced $(113.5 \pm 29.6$ vs. $107.3 \pm 28.9 \mathrm{mg} / \mathrm{dL})$ along with high-density lipoprotein $(54.6 \pm 18.1 \mathrm{vs} .59 .0$ $\pm 18.8 \mathrm{mg} / \mathrm{dL})$, TSH $(2.1 \pm 1.1$ vs. $2.6 \pm 1.2 \mathrm{mIU} / \mathrm{mL})$, and free T4 $(0.9 \pm 0.1 \mathrm{vs} .1 .12 \pm 0.2 \mathrm{ng} / \mathrm{dL})$ increase after physical exercise training. Plasma 8-isoprostane levels ( $17.24 \pm 7.9$ vs. $29.11 \pm 17.44 \mathrm{pg} / \mathrm{mL})$ and DNA damage $(34.16 \pm 7.1 \mathrm{vs} .45 .96 \pm 5.8 \%$ DNA in tail) were also higher after physical training. No changes were observed in chromosomal damage levels. These results suggest that 16 weeks of combined exercise training 3 times per week is effective in reducing body fat but also increases oxidative stress and DNA damage in obese women.
\end{abstract}

\section{Introduction}

Obesity is characterized as abnormal or excessive fat accumulation that presents a risk to health. The body mass index (BMI) (the division of a person's weight-in kilograms-by the square height-in meters) is classically used to classify obesity condition, which in this context is stratified into five categories: Grade I (BMI between 30 and $34.9 \mathrm{~kg} / \mathrm{m}^{2}$ ), Grade II (BMI between 35.0 and $39.9 \mathrm{~kg} / \mathrm{m}^{2}$ ), Grade III (BMI $\geq 40$ $\left.\mathrm{kg} / \mathrm{m}^{2}\right)$, Grade IV $\left(B M I \geq 50 \mathrm{~kg} / \mathrm{m}^{2}\right)$, and very severe-Grade $\mathrm{V}\left(\mathrm{BMI} \geq 60 \mathrm{~kg} / \mathrm{m}^{2}\right)$ [1]. Obesity has been recognized as a major underlying factor in the pathogenesis of several diseases such as type 2 diabetes, coronary heart disease, stroke, and cancer [2]. Its prevalence has reached pandemic proportions representing an important health threat, and the costs related to the treatment of this disease achieved extremely elevated levels [3-5].

A variety of studies have demonstrated that obese individuals have higher reactive oxygen species (ROS) levels in several tissues when compared to their eutrophic counterparts [6-8]. Moreover, they seem to have lower antioxidant defense than nonobese individuals [9]. The overproduction of ROS along with the impairment of their detoxification leads to increased ROS availability that can cause oxidative modifications in lipids, proteins, and DNA [10]. The interaction between ROS and DNA is related to a wide range of 
structural modifications in the DNA molecule, such as oxidation of purines and pyrimidines, apurinic/apyrimidinic (abasic) DNA sites, and single- and double-stranded breaks [11]. Epidemiological studies convincingly show that obese adults have an augmented risk of developing several types of cancer. Besides, studies suggest that the genomic instability generated by oxidative stress in obese individuals is a critical factor in the development of this pathology [12].

There is a large body of evidence demonstrating the beneficial effects of periodized physical exercise on obese people health. For instance, the anti-inflammatory response induced by physical exercise can improve general health, affecting blood vessels, neurons, endocrine system, skeletal muscle, adipose tissue, and immune function [13-15]. Furthermore, moderate chronic physical exercise reduces oxidative stress and molecular damage, both by decreasing ROS production and increasing antioxidant capacity [16]. It has been shown that acute physical exercise promotes a transient prooxidative state that is involved in the activation of multiple redox-sensitive signaling pathways responsible for the cellular adaptation, leading to increased resistance to stress in a chronic perspective [17-19]. However, it is determinant to note that individual characteristics, such as gender, age, and pathological conditions, directly influence the physiological outcome induced by physical exercise. Importantly, obesity is related to reduced overall physical capacity, mainly aerobic capacity, which is a risk factor for pathophysiological changes on different organs and in general metabolism [20]. In this regard, obese individuals require more control over the training prescription, once due to their basal lowgrade inflammation and redox imbalance they seem to be more susceptible to exercise-induced oxidative stress [21].

The American College of Sports Medicine proposes the prescription of aerobic, muscle strengthening, and flexibility exercises for eutrophic adults, and the combination of aerobic and strength exercises seems to be efficient to induce health benefits in eutrophic and also in obese individuals [22]. It has been reported that combined exercise (aerobic plus strength) reduces the oxidation of biomolecules and DNA damage and increases antioxidant defense [23-25], but to the best of our knowledge, there are no studies performed exclusively with obese women. Thus, the current study is aimed at determining the effects of 16 weeks of combined physical exercise on markers of oxidative stress and DNA damage in obese women.

\section{Material and Methods}

2.1. Data Sharing Statement. The data that support the findings of this study are available from the corresponding author upon reasonable request.

2.2. Participants. Women aged 32 to 63 years $(48 \pm 11.7)$ with a BMI between 30 and $39.99 \mathrm{~kg} \cdot \mathrm{m}^{-2}$ were recruited. All participants were nonsmoking, not taking hormonal contraceptives, not dieting, and sedentary (defined as exercising \pm 40 min per week during the 6 months before baseline testing). Figure 1 shows the flow of participants through the trial. All participants gave written informed consent. The study

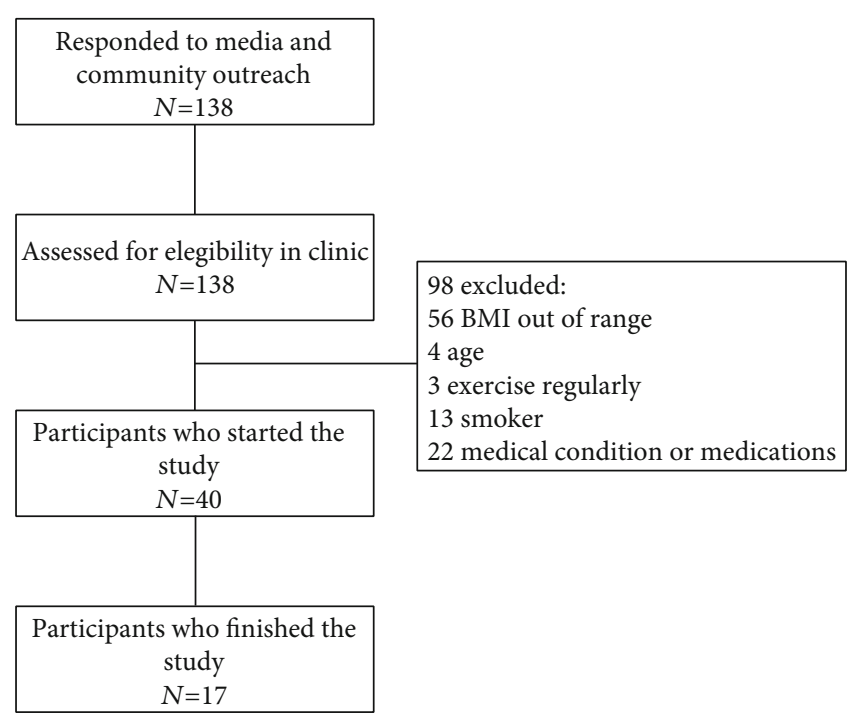

Figure 1: Flow of participants through the trial.

was approved by the Clementino Fraga Filho Hospital Ethics Committee for research on humans (approval number: 85529318.1.0000.5257).

2.3. Physical Exercise Intervention. The subjects followed the exercise training over 16 weeks, with 3 sessions per week, on nonconsecutive days. Each session was divided into 3 parts: aerobic exercise (20 minutes), strength exercise (35 minutes), and stretching exercise (5 minutes). The first treadmill session lasted 15 minutes in weeks 1 to 4 and 20 minutes in weeks 5 to 16 . The intensity of aerobic exercise started at $40 \%$ of the heart rate reserve (HRR) and increased by $10 \%$ every 4 weeks, ending at 16 weeks with $70 \%$ of $\mathrm{HRR}$ (Figure 2(a)). The strength exercise sequence was hierarchized according to the size of the muscle group, from large to small-bench press, leg press, leg curl, leg extension, latissimus dorsi, abdominals, and arm flexion. The intensity of strength training started at $50 \%$ of one-repetition maximum (1RM) and increased by $10 \%$ every 4 weeks, ending at 16 weeks with 65 to $75 \%$ of $1 \mathrm{RM}$ (Figure 2(b)). Two sets of each strength exercise were executed in the first 4 weeks, and 3 sets in the following weeks, with 8-12 repetitions and a rest interval of 1 minute between the series.

2.4. Anthropometric Measurements. Height $(\mathrm{cm})$ and total body weight $(\mathrm{kg})$ were measured according to the international standards for anthropometric assessment. To evaluate height $(\mathrm{cm})$, a stadiometer (Alturexata) with a scale range of $1 \mathrm{~mm}$ was used, and body mass $(\mathrm{kg})$ was measured to the nearest $0.1 \mathrm{~kg}$ using a digital scale (Philips, type $\mathrm{HF}$ 351/00). Waist circumference (WC) was used taking the umbilicus point as a reference. The evaluation of body composition was performed using the multifrequency electrical bioimpedance apparatus (Biodynamics ${ }^{\circledR}$ model 450 ).

2.5. Blood Sampling. Blood samples were obtained from a forearm vein of each participant in heparinized Vacutainer tubes before and after 16 weeks of exercise training (72 hours 


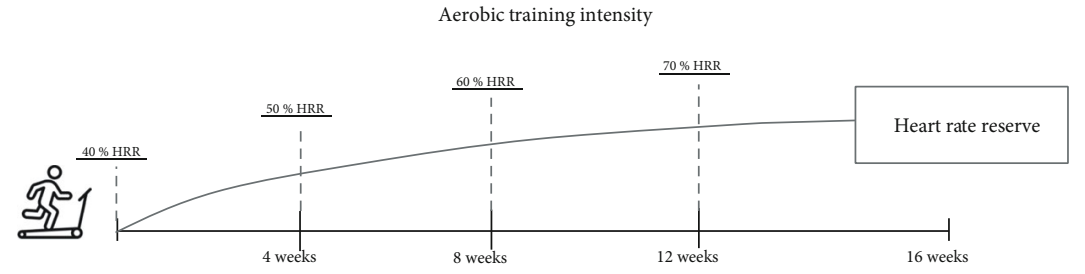

(a)

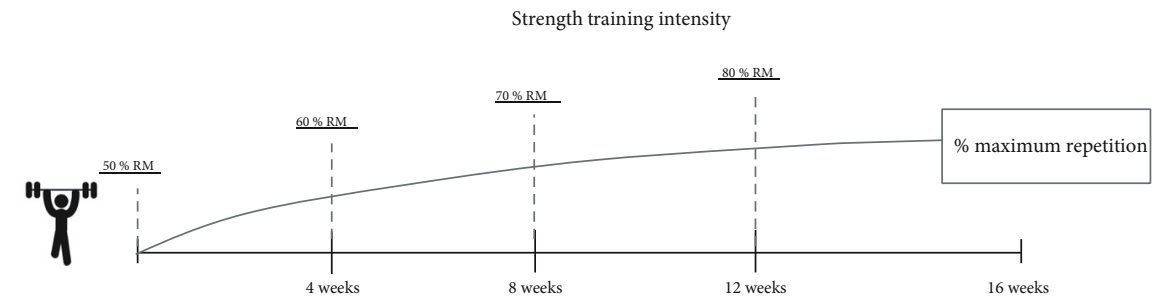

(b)

FIgURE 2: Periodization exercise training. (a) Aerobic training intensity progression based on heart rate reserve (HRR). (b) Strength training intensity progression based on $\%$ of maximum repetition.

after the last exercise session). Blood samples were collected at 8:00 AM after a $12 \mathrm{~h}$ fast and immediately centrifuged at $1000 \times \mathrm{g}$ for $15 \mathrm{~min}$ at ambient temperature to separate serum/plasma from red blood cell pellets. The samples were immediately frozen and stored at $-70^{\circ} \mathrm{C}$ until analysis.

2.6. Biochemical and Hormonal Measurements. Blood glucose was analyzed by spectrophotometry (Beckman Coulter). HDL-cholesterol and LDL-cholesterol serum levels were evaluated by colorimetric tests (Beckman Coulter). Glycated hemoglobin was evaluated by high-performance liquid chromatography. Fasting serum thyrotropin (TSH), thyroxine (T4), and free triiodothyronine (T3) levels were measured using specific immunoassays (Immunolite 2000, Siemens). Detection limits were $0.004 \mu \mathrm{IU} / \mathrm{mL}, 0.22 \mathrm{ng} / \mathrm{dL}$, and $0.5 \mathrm{pg} / \mathrm{mL}$ for TSH, free T4, and total T3, respectively. Serum levels of leptin (range: 62.5-4000 pg/mL) were measured using a commercial enzyme linked-immunosorbent assay (ELISA) kit (Boster Biological Technology Co Ltd., USA; cat. no: EK0437). The intra- and interassay coefficients of variation and sensitivity for leptin were $6.7 \%$ and $8 \%$, respectively.

2.7. Oxidative Stress Biomarkers. Superoxide dismutase (SOD) activity and glutathione peroxidase (GPX) activity were measured in the serum by colorimetric assay kits (SOD Assay kit, Cayman Chemical Company, catalog number 706002, USA, and GPX Assay kit, Cayman Chemical Company, catalog number 703102, USA), following the manufacturer's instructions. 8-Isoprostane levels were measured in the plasma by a colorimetric assay kit (8-isoprostane assay kit, Cayman Chemical Company, catalog number 516351, USA), following the manufacturer's instructions. The absorbance was read in a microplate reader (Victor X4, PerkinElmer, Norwalk, Conn., USA) at $450 \mathrm{~nm}$ for SOD, $340 \mathrm{~nm}$ for GPX, and $412 \mathrm{~nm}$ for 8 -isoprostane. The range of the SOD assay was from 0.005 to $0.050 \mathrm{U} \mathrm{SOD} / \mathrm{mL}$, and intra-assay variation was $3.2 \%$. The intra-assay coefficient of variation of the GPX assay was $5.7 \%$. The sensitivity of the 8 -isoprostane assay was $3 \mathrm{pg} / \mathrm{mL}$, and intra-assay variation was $7.2 \%$. All samples were measured in the same assay.

2.8. Comet Assay. $5 \mu \mathrm{L}$ of whole blood was suspended in $100 \mu \mathrm{L}$ of $0.5 \%$ low melting point agarose in PBS. The cells were then homogenously spread onto two microscope slides precoated with $1.5 \%$ agarose, immediately covered with coverslips, and kept at $4^{\circ} \mathrm{C}$ for $10 \mathrm{~min}$. The solidified slides were immersed in cell lysis buffer $(2.5 \mathrm{M} \mathrm{NaCl}, 100 \mathrm{mM} \mathrm{Na} 2$ EDTA, 10 M Tris, $10 \%$ DMSO, 1\% Triton X-100, pH 10) at $4^{\circ} \mathrm{C}$ overnight. The slides were then placed horizontally in an electrophoresis chamber with cold alkaline buffer (300 mM NaOH, $1 \mathrm{mM}$ EDTA, $\mathrm{pH}>13$ ) for $20 \mathrm{~min}$, and electrophoresis was performed for $25 \mathrm{~min}$ at $25 \mathrm{~V}$ and $300 \mathrm{~mA}$. Then, slides were neutralized with three $5 \mathrm{~min}$ washes with neutralization buffer (0.4 M Tris, $\mathrm{pH} 7.5)$ and fixed with ice-cold $100 \%$ ethanol. Finally, the slides were stained with DAPI and imaged with a fluorescence microscope at a magnification of $200 x$. At least 100 comets per slide were scored, in duplicate, using the OpenComet v1.3.1 software. The results were plotted by the percentage of tail DNA content [26].

2.9. Cytokinesis-Block Micronucleus Cytome Assay. The assay was performed following specifications according to the Fenech protocol [27], with some modifications. $400 \mu \mathrm{L}$ of heparinized whole blood was added to $4.5 \mathrm{~mL}$ of DMEM medium plus $100 \mu \mathrm{L}$ of phytohemagglutinin (Gibco), and the samples were incubated at $37^{\circ} \mathrm{C}$ and $5 \% \mathrm{CO}_{2}$. After 44 hours, cytochalasin $\mathrm{B}$ at a final concentration of $5 \mu \mathrm{g} / \mathrm{mL}$ was added to the samples and incubated for further 28 hours to block cytokinesis, totalizing 72 hours of incubation. Thereafter, samples were washed with PBS and centrifuged at $1000 \mathrm{rpm}$ for 5 minutes. The supernatant was discarded, and the lymphocytes were collected with ice-cold hypotonic solution ( $\mathrm{KCl} 0.075 \mathrm{M}$ ) for red cell lysis. After another centrifugation, the supernatant was discarded and fixed with $5 \mathrm{~mL}$ 
of methanol/acetic acid solution $(3: 1 v / v)$, followed by centrifugation at $1500 \mathrm{rpm}$ for 5 minutes for 3 times. Finally, $1 \mathrm{~mL}$ of fixative solution was added for the preparation of the slides. The slides were stained with $10 \%$ Giemsa solution for optical microscopy analysis. Binuclear cells were scored, as well as micronuclei (MN), nucleoplasmic bridges (NPBs), and nuclear buds (NBUDs), as proposed by Fenech [27]. 3.000 binucleated cells were scored per treatment, and the results were expressed in the number of occurrences of alterations per 1.000 binucleated cells.

2.10. Statistical Analysis. All the results are expressed as the mean \pm standard deviation of the mean and were analyzed by a paired $T$-test using the GraphPad Prism software (version 5.01, GraphPad Software Inc., San Diego, USA). The minimum level of significance was set at $P<0.05$.

\section{Results}

Herein, we report results from the 17 women who completed the entire study. The baseline anthropometric characteristics of the participants are listed in Table 1. As observed, at baseline, participants had a BMI mean of $33.8 \mathrm{~kg} \cdot \mathrm{m}^{-2}$, which was significantly reduced to $32.6 \mathrm{~kg} \cdot \mathrm{m}^{-2}$ after the physical exercise intervention. Moreover, body fat percentage and waist circumference were also reduced, while fat-free mass increased after 16 weeks of physical exercise.

The physical exercise protocol was found to decrease blood glucose in the subjects, but there was no effect concerning serum levels of glycated hemoglobin, total lipids, and LDL (Table 2). Besides, serum HDL levels were significantly elevated. Regarding hormonal measurements, free T4 and TSH serum levels were significantly increased by exercise training, and no changes were observed for serum-free T3 and leptin levels.

There was no effect of physical exercise on SOD (Figure 3(a)) and GPX activities (Figure 3(b)). However, 8isoprostane, a marker of lipid peroxidation, was higher after exercise training $(P<0.05)$ (Figure 3(c)).

The alkaline comet assay was performed to determine the DNA damage in peripheral blood cells of obese individuals before and after physical exercise training. We noticed that 16 weeks of combined physical exercise training increased DNA damage levels $(P=0.0002)$ in the subjects (Figure 4$)$.

Interestingly, no differences between groups were found for the different parameters evaluated in the micronucleus assay (Table 3 ).

\section{Discussion}

Women are particularly affected by the obesity epidemic, and their greater prevalence becomes only manifested in adulthood [28]. Recent estimates reveal that the incidence of obesity will reach $18 \%$ in men and $21 \%$ in women by 2025 [29]. The sex-related differences in obesity have been attributed to nutrition, lifestyle, behavior, and environmental differences between men and women $[30,31]$. In the current study, we investigated the effect of 16 weeks of combined physical exercise on redox markers and DNA damage in obese women.
TABle 1: Anthropometric characteristics of 17 obese women prior to and following 16 weeks of combined physical exercise.

\begin{tabular}{lcc}
\hline & $\begin{array}{c}\text { Preexercise } \\
\text { training }\end{array}$ & $\begin{array}{c}\text { Postexercise } \\
\text { training }\end{array}$ \\
\hline Height $(\mathrm{cm})$ & $156 \pm 4.43$ & N/A \\
Weight $(\mathrm{kg})$ & $83.2 \pm 9.6$ & $80.2 \pm 9.6^{* *}$ \\
BMI $\left(\mathrm{kg} \cdot \mathrm{m}^{-2}\right)$ & $33.8 \pm 3.6$ & $32.6 \pm 3.7^{* *}$ \\
Body fat $(\%)$ & $40.2 \pm 2.6$ & $39.0 \pm 3.2^{*}$ \\
Fat-free mass $(\mathrm{kg})$ & $59.9 \pm 2.9$ & $60.7 \pm 3.1^{*}$ \\
$\begin{array}{l}\text { Waist circumference } \\
(\mathrm{cm})\end{array}$ & $99.3 \pm 9.4$ & $94.1 \pm 8.8^{* * *}$ \\
\hline
\end{tabular}

${ }^{*} P<0.05 ;{ }^{* *} P<0.01 ;{ }^{* * *} P<0.001$. Data were expressed as the mean $\pm \mathrm{SD}$. BMI: body mass index; LDL: low-density lipoprotein; HDL: high-density lipoprotein; N/A: not applicable.

TABLE 2: Biochemical and hormonal measurements of 17 obese women prior to and following 16 weeks of combined physical exercise.

\begin{tabular}{lcc}
\hline & $\begin{array}{c}\text { Preexercise } \\
\text { training }\end{array}$ & $\begin{array}{c}\text { Postexercise } \\
\text { training }\end{array}$ \\
\hline Glucose $(\mathrm{mg} / \mathrm{dL})$ & $113.5 \pm 29.6$ & $107.3 \pm 28.9^{*}$ \\
Glycated hemoglobin & $5.8 \pm 0.9$ & $5.9 \pm 1.1$ \\
$(\%)$ & $683.0 \pm 228.3$ & $630.1 \pm 119.6$ \\
Total lipids (mg/dL) & $54.6 \pm 18.1$ & $59.0 \pm 18.8^{*}$ \\
HDL $(\mathrm{mg} / \mathrm{dL})$ & $140.6 \pm 72.2$ & $116.3 \pm 28.8$ \\
LDL $(\mathrm{mg} / \mathrm{dL})$ & $2.5 \pm 0.9$ & $3.2 \pm 2.0$ \\
Free T3 $(\mathrm{pg} / \mathrm{mL})$ & $0.9 \pm 0.1$ & $1.12 \pm 0.2^{* * *}$ \\
Free T4 $(\mathrm{ng} / \mathrm{dL})$ & $2.1 \pm 1.1$ & $2.6 \pm 1.2^{* *}$ \\
TSH $(\mathrm{mIU} / \mathrm{mL})$ & $29.7 \pm 4.9$ & $29.8 \pm 2.8$ \\
Leptin $(\mathrm{mg} / \mathrm{dL})$ &
\end{tabular}

${ }^{*} P<0.05 ;{ }^{* *} P<0.01 ;{ }^{* *} P<0.001$. Data were expressed as the mean $\pm \mathrm{SD}$. LDL: low-density lipoprotein; HDL: high-density lipoprotein; TSH: thyroid-stimulating hormone.

Our results demonstrate that the combined exercise intervention was effective in parameters related to body composition, such as a decrease in body weight, BMI, waist circumference, and fat mass, along with elevations of fatfree mass. However, we found an increase in serum 8-isoprostane, a marker of lipid peroxidation, and leukocyte DNA strand breaks.

Our study showed that after 16 weeks of exposure to training, obese women had a reduction in blood glucose, which is a well-established effect of physical exercise once it is capable of enhancing tissue sensitivity to insulin. Besides, alterations in body weight and composition have also been shown to affect tissue sensitivity to insulin [32, 33]. We observed an increase in HDL, which is related to beneficial effects on the metabolism of obese individuals and contributes to reducing chronic low-grade inflammation [34]. Moreover, serum T4 and TSH levels were increased by physical exercise, but not T3 levels. As T3 is the active hormone, thyroid hormone signaling probably was unaltered. Further studies are necessary to explain the observed changes in T4 


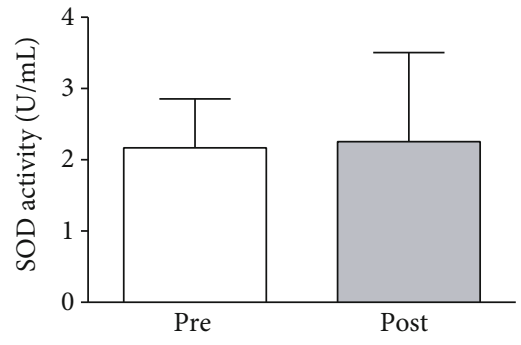

(a)

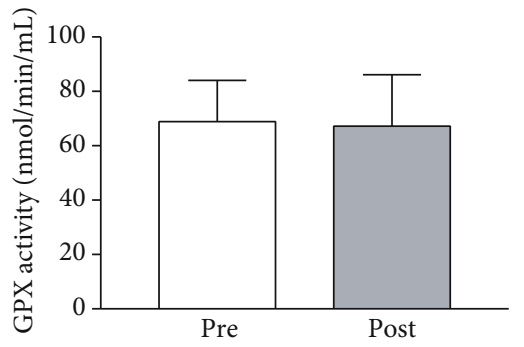

(b)

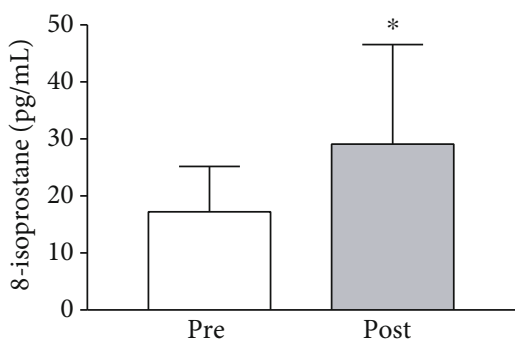

(c)

FIGURE 3: Oxidative stress biomarkers in obese women pre- and post-16 weeks of combined physical exercise. Serum superoxide dismutase activity (a), serum glutathione peroxidase activity (b), and plasma 8-isoprostane levels (c) were measured by spectrophotometry. The results are expressed as the mean \pm SD. ${ }^{*} P<0.05$.

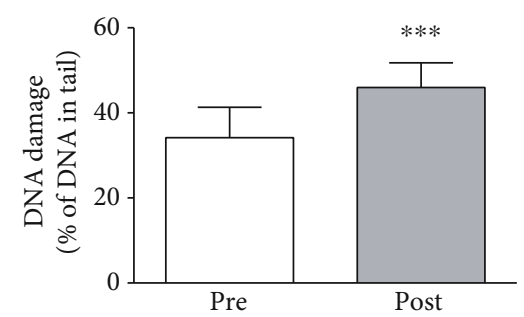

FIGURE 4: DNA damage in obese women pre- and post-16 weeks of combined physical exercise assessed by the comet assay. The results are expressed as the mean $\pm \mathrm{SD} .{ }^{* * *} P<0.001$.

TABLE 3: Number of micronuclei, nuclear buds, and nucleoplasmic bridges in 1000 binucleated blood lymphocytes of 17 obese women prior to and following 16 weeks of physical exercise.

\begin{tabular}{lcc}
\hline & Preexercise training & Postexercise training \\
\hline Micronuclei & $66.5 \pm 45.1$ & $76.5 \pm 54.9$ \\
$\begin{array}{l}\text { Nuclear buds } \\
\begin{array}{l}\text { Nucleoplasmic } \\
\text { bridges }\end{array}\end{array}$ & $3.6 \pm 7.4$ & $2.8 \pm 3.7$ \\
\hline
\end{tabular}

Data were expressed as the mean \pm SD.

and TSH. Serum levels of total cholesterol, triglycerides, LDL, leptin, and glycated hemoglobin were not affected by combined exercise, so we postulate that it might necessitate a longer period of intervention to observe an improvement in those parameters.

Herein, we show that 16 weeks of the combined exercise was able to increase lipid peroxidation, without changes in serum GPX and SOD activities on obese women. Regarding the specific literature, few studies have been conducted in obese individuals evaluating the effect of combined exercise training on redox homeostasis. Overweight elderly women who performed moderate-intensity combined aerobicresistance exercise training 3 times a week for at least 18 months had a decrease in total peroxides and an increase in total antioxidant capacity [24]. Medeiros et al. demonstrated an enhanced lipid peroxidation and a reduction of serum GPX activity in obese individuals submitted to 26 sessions of combined exercise 3 times a week, with no changes in the other two oxidative stress biomarkers, protein carbonyl and sulfhydryl. Interestingly, when the subjects performed the same 26 sessions 5 times a week, no differences were observed in lipid peroxidation between groups, and a decrease of protein carbonyl was found [35]. So, the longitudinal continuity and frequency seem to be a determinant in the modulation of redox homeostasis, once training performed for longer periods and more frequently would be related to better responses.

Moreover, obese individuals are more susceptible to redox homeostasis challenges by having higher ROS levels and decreased antioxidant defense. It has been shown that an acute increase in serum lipids elevates F2-isoprostane levels more markedly in obese than in lean individuals [36]. Physical exercise increases ROS generation acutely, being much more pronounced in obese in comparison to eutrophic subjects due to their basal oxidative redox state $[37,38]$. Thus, it is possible that the fine-tuning redox-mediated signaling required to correctly activate the molecular effectors in response to exercise was not reached in our study subjects because of the conditions described above. The lack of effect of physical exercise on the activity of the antioxidant enzymes SOD and GPX corroborates this hypothesis. Furthermore, we take into consideration that our sample is composed exclusively of women, and sex would be a pertinent factor in the physiological response to exercise [39]. Moreover, more studies are necessary to elucidate this question because only 17 individuals were evaluated in our study.

The mechanism by which physical exercise influences DNA stability is not completely elucidated, but the prooxidative state found during/after the exercise session seems to be involved. In our study, utilizing the alkaline comet assay (a method capable of detecting DNA double-strand breaks, single-strand breaks, alkali-labile sites, DNA-DNA/DNAprotein cross-linking, and incomplete excision repair sites at a single cell level), we observed higher levels of leukocyte DNA damage in obese women after 16 weeks of combined exercise [26]. Several investigations reported the occurrence of DNA damage in white blood cells following different types of acute exercise such as high-intensity, short-duration [4042], moderate-intensity and duration [42], and moderateintensity endurance [43]. Hartmann et al. showed that healthy men supplemented with vitamin E ( $1.200 \mathrm{mg}$ daily) for 14 days before a run had their exercise-induced DNA damage completely abrogated in 4 of the 5 volunteers, while 
the lipid peroxidation increase after exercise did not occur [40]. Another study described a $62 \%$ reduction in the DNA damage rate in women taking the antioxidants vitamin $\mathrm{C}$ (1.000 mg) and RRR-a-tocopheryl acetate (400 IU) during 6 weeks before an ultramarathon race [44]. Here, we observed an increase in lipid peroxidation after 16 weeks of combined exercise training that may be related to the higher levels of DNA damage, since lipid peroxidation products have been shown to form DNA adducts mediating DNA damage associated with oxidative stress [45]. However, more experiments are needed to prove this hypothesis.

To the best of our knowledge, no studies evaluated the effect of combined exercise training on DNA damage in obese women. We found only one study evaluating the effect of 16 weeks of combined exercise, but the volunteers were healthy men [23]. In this study, combined exercise training led to a decrease in DNA single-strand breaks and FPG-sensitive sites. Once DNA repair was not affected by training, the authors proposed that a reduction of ROS production and/or an increase of antioxidant defense were responsible for decreased oxidative DNA damage, since the exercise intervention reduced lipid peroxidation and elevated total antioxidant capacity [23]. This observation suggests that the lack of adaptation related to redox homeostasis in the present study may be associated with obesity, probably due to the high basal levels of oxidative stress found in these individuals [23]. Besides, a deficient repair of the DNA molecule could also be involved. To gain more insights into the biological significance of the observed effects on DNA by the comet assay, it is necessary to compare these effects with other endpoints of genotoxicity. Thus, we analyzed chromosome breakage and chromosome loss by the micronucleus assay. Despite the results found of augmented DNA damage, no change in micronucleus frequency was detected when comparing pre- and postexercise results. This suggests that DNA lesions are probably repaired and do not result in chromosome damage.

\section{Conclusions}

In summary, we demonstrate that 16 weeks of combined physical exercise performed 3 times per week presented positive effects related to body composition and blood biochemical changes, but it was not sufficient to increase antioxidant defense and resulted in increased lipid peroxidation and DNA damage in obese women, without changes in chromosome breakage. Thus, it is important to note that controlling training variables (volume, intensity, weekly frequency, and duration) should be considered according to individual physiological conditions, especially for obese women.

\section{Data Availability}

All data used to support the findings of this study are available from the corresponding author upon request.

\section{Ethical Approval}

All procedures performed in studies involving human participants were in accordance with the ethical standards of the institutional research committee (Clementino Fraga Filho Hospital Ethics Committee for research on humans, Rio de Janeiro, Brazil). The study was approved by this ethics committee and is registered under study number 85529318.1.0000.5257.

\section{Consent}

Informed consent was obtained from all individual participants included in the study prior to any study-related activity.

\section{Conflicts of Interest}

The authors declare that they have no conflicts of interest.

\section{Acknowledgments}

This work was supported by Conselho Nacional de Desenvolvimento Científico e Tecnológico (CNPq), Fundação de Amparo à Pesquisa do Estado do Rio de Janeiro (FAPERJ), and Coordenação de Aperfeiçoamento de Pessoal de Nível Superior (CAPES).

\section{References}

[1] P. Poirier, M. A. Alpert, L. A. Fleisher et al., "Cardiovascular evaluation and management of severely obese patients undergoing surgery," Circulation, vol. 120, no. 1, pp. 86-95, 2009.

[2] K. E. Foster-Schubert and D. E. Cummings, "Emerging therapeutic strategies for obesity," Endocrine Reviews, vol. 27, no. 7, pp. 779-793, 2006.

[3] D. D. Kim and A. Basu, "Estimating the medical care costs of obesity in the United States: systematic review, meta-analysis, and empirical analysis," Value in Health, vol. 19, no. 5, pp. 602-613, 2016.

[4] M. Fried, V. Yumuk, J. M. Oppert et al., "Interdisciplinary European guidelines on metabolic and bariatric surgery," Rozhledy v Chirurgii, vol. 93, no. 7, pp. 366-378, 2014.

[5] S. L. James, C. D. Castle, Z. V. Dingels et al., "Correction:Global injury morbidity and mortality from 1990 to 2017: results from the Global Burden of Disease Study 2017," Injury Prevention, vol. 26, article i165, Supplement 1, 2020.

[6] D. P. Jones, "Radical-free biology of oxidative stress," American Journal of Physiology. Cell Physiology, vol. 295, no. 4, pp. C849-C868, 2008.

[7] H. K. Vincent and A. G. Taylor, "Biomarkers and potential mechanisms of obesity-induced oxidant stress in humans," International Journal of Obesity, vol. 30, no. 3, pp. 400-418, 2006.

[8] S. Furukawa, T. Fujita, M. Shimabukuro et al., "Increased oxidative stress in obesity and its impact on metabolic syndrome," The Journal of Clinical Investigation, vol. 114, no. 12, pp. 1752 1761, 2004.

[9] F. Amirkhizi, F. Siassi, M. Djalali, and S. H. Shahraki, "Impaired enzymatic antioxidant defense in erythrocytes of 
women with general and abdominal obesity," Obesity Research \& Clinical Practice, vol. 8, no. 1, pp. e26-e34, 2014.

[10] M. Włodarczyk and G. Nowicka, "Obesity, DNA damage, and development of obesity-related diseases," International Journal of Molecular Sciences, vol. 20, no. 5, 2019.

[11] T. B. Kryston, A. B. Georgiev, P. Pissis, and A. G. Georgakilas, "Role of oxidative stress and DNA damage in human carcinogenesis," Mutation Research/Fundamental and Molecular Mechanisms of Mutagenesis, vol. 711, no. 1-2, pp. 193-201, 2011.

[12] T. Setayesh, A. Nersesyan, M. Mišík et al., "Impact of obesity and overweight on DNA stability: few facts and many hypotheses," Mutation Research, vol. 777, pp. 64-91, 2018.

[13] M. Gleeson, N. C. Bishop, D. J. Stensel, M. R. Lindley, S. S. Mastana, and M. A. Nimmo, "The anti-inflammatory effects of exercise: mechanisms and implications for the prevention and treatment of disease," Nature Reviews. Immunology, vol. 11, no. 9, pp. 607-615, 2011.

[14] V. Frodermann, D. Rohde, G. Courties et al., "Exercise reduces inflammatory cell production and cardiovascular inflammation via instruction of hematopoietic progenitor cells," Nature Medicine, vol. 25, no. 11, pp. 1761-1771, 2019.

[15] B. K. Pedersen, "Anti-inflammatory effects of exercise: role in diabetes and cardiovascular disease," European Journal of Clinical Investigation, vol. 47, no. 8, pp. 600-611, 2017.

[16] M.-C. Gomez-Cabrera, E. Domenech, and J. Viña, "Moderate Exercise Is an Antioxidant: Upregulation of Antioxidant Genes by Training," Free Radical Biology and Medicine, vol. 44, no. 2, pp. 126-131, 2008.

[17] Z. Radak, Z. Zhao, E. Koltai, H. Ohno, and M. Atalay, "Oxygen consumption and usage during physical exercise: the balance between oxidative stress and ROS-dependent adaptive signaling," Antioxidants \& Redox Signaling, vol. 18, no. 10, pp. 1208-1246, 2013.

[18] F. He, J. Li, Z. Liu, C.-C. Chuang, W. Yang, and L. Zuo, "Redox mechanism of reactive oxygen species in exercise," Frontiers in Physiology, vol. 7, 2016.

[19] C. Scheele, S. Nielsen, and B. K. Pedersen, "ROS and Myokines Promote Muscle Adaptation to Exercise," Trends in Endocrinology \& Metabolism, vol. 20, no. 3, pp. 95-99, 2009.

[20] T. Church, "Exercise in obesity, metabolic syndrome, and diabetes," Progress in Cardiovascular Diseases, vol. 53, no. 6, pp. 412-418, 2011.

[21] A. Petridou, A. Siopi, and V. Mougios, "Exercise in the management of obesity," Metabolism, vol. 92, pp. 163-169, 2019.

[22] J. E. Donnelly, S. N. Blair, J. M. Jakicic, M. M. Manore, J. W. Rankin, and B. K. Smith, "Appropriate physical activity intervention strategies for weight loss and prevention of weight regain for adults," Medicine \& Science in Sports \& Exercise, vol. 41, no. 2, pp. 459-471, 2009.

[23] J. P. Soares, A. M. Silva, M. M. Oliveira, F. Peixoto, I. Gaivão, and M. P. Mota, "Effects of combined physical exercise training on DNA damage and repair capacity: role of oxidative stress changes," Age, vol. 37, no. 3, p. 9799, 2015.

[24] A. L. L. Bachi, M. P. Barros, R. P. Vieira et al., "Combined exercise training performed by elderly women reduces redox indexes and proinflammatory cytokines related to atherogenesis," Oxidative Medicine and Cellular Longevity, vol. 2019, Article ID 6469213, 9 pages, 2019.

[25] M. P. Mota, Z. A. dos Santos, J. F. P. Soares et al., "Intervention with a combined physical exercise training to reduce oxidative stress of women over 40 years of age," Experimental Gerontology, vol. 123, pp. 1-9, 2019.

[26] R. R. Tice, E. Agurell, D. Anderson et al., "Single cell gel/comet assay: guidelines for in vitro and in vivo genetic toxicology testing," Environmental and Molecular Mutagenesis, vol. 35, no. 3, pp. 206-221, 2000.

[27] M. Fenech, "Cytokinesis-block micronucleus cytome assay," Nature Protocols, vol. 2, no. 5, pp. 1084-1104, 2007.

[28] The GBD 2015 Obesity Collaborators, "Health effects of overweight and obesity in 195 countries over 25 years," The New England Journal of Medicine, vol. 377, no. 1, pp. 13-27, 2017.

[29] NCD Risk Factor Collaboration (NCD-RisC), "Trends in adult body-mass index in 200 countries from 1975 to 2014: a pooled analysis of 1698 population-based measurement studies with 19.2 million participants," The Lancet, vol. 387, no. 10026, pp. 1377-1396, 2016.

[30] J. C. Jones-Smith, P. Gordon-Larsen, A. Siddiqi, and B. M. Popkin, "Cross-national comparisons of time trends in overweight inequality by socioeconomic status among women using repeated cross-sectional surveys from 37 developing countries, 1989-2007," American Journal of Epidemiology, vol. 173, no. 6, pp. 667-675, 2011.

[31] L. D. Howe, R. Patel, and B. Galobardes, "Commentary: tipping the balance: wider waistlines in men but wider inequalities in women," International Journal of Epidemiology, vol. 39, no. 2, pp. 404-405, 2010.

[32] D. E. Kelley and B. H. Goodpaster, "Effects of physical activity on insulin action and glucose tolerance in obesity," Medicine \& Science in Sports \& Exercise, vol. 31, Supplement 1, 1999.

[33] R. A. DeFronzo, R. S. Sherwin, and N. Kraemer, "Effect of physical training on insulin action in obesity," Diabetes, vol. 36, no. 12, pp. 1379-1385, 1987.

[34] N. J. Woudberg, A. E. Mendham, A. A. Katz, J. H. Goedecke, and S. Lecour, "Exercise intervention alters HDL subclass distribution and function in obese women," Lipids in Health and Disease, vol. 17, no. 1, p. 232, 2018.

[35] N. da Silva Medeiros, F. G. de Abreu, A. S. Colato et al., "Effects of concurrent training on oxidative stress and insulin resistance in obese individuals," Oxidative Medicine and Cellular Longevity, vol. 2015, Article ID 697181, 6 pages, 2015.

[36] M. P. Stojiljkovic, H. F. Lopes, D. Zhang, J. D. Morrow, T. L. Goodfriend, and B. M. Egan, "Increasing plasma fatty acids elevates F2-isoprostanes in humans: implications for the cardiovascular risk factor cluster," Journal of Hypertension, vol. 20, no. 6, pp. 1215-1221, 2002.

[37] E. C. Wuorinen, R. Page, and S. H. Wuorinen, “Acute and chronic varied exercise intensity effects on total antioxidant capacity and protein carbonylation," The FASEB Journal, vol. 31, no. 1, article 839.26, 2017.

[38] H. Youssef, C. Groussard, J. Pincemail et al., "Exercise-induced oxidative stress in overweight adolescent girls: roles of basal insulin resistance and inflammation and oxygen overconsumption," International Journal of Obesity, vol. 33, no. 4, pp. 447-455, 2009.

[39] I. Pinchuk, D. Weber, B. Kochlik et al., "Gender- and agedependencies of oxidative stress, as detected based on the steady state concentrations of different biomarkers in the MARK-AGE study," Redox Biology, vol. 24, article 101204, 2019.

[40] A. Hartmann, S. Pfuhler, C. Dennog, D. Germadnik, A. Pilger, and G. Speit, "Exercise-induced DNA effects in human 
leukocytes are not accompanied by increased formation of 8hydroxy-2'-deoxyguanosine or induction of micronuclei," Free Radical Biology \& Medicine, vol. 24, no. 2, pp. 245-251, 1998.

[41] M. Mars, S. Govender, A. Weston, V. Naicker, and A. Chuturgoon, "High intensity exercise: a cause of lymphocyte apoptosis?," Biochemical and Biophysical Research Communications, vol. 249, no. 2, pp. 366-370, 1998.

[42] A. Niess, A. Hartmann, M. Grünert-Fuchs, B. Poch, and G. Speit, "DNA damage after exhaustive treadmill running in trained and untrained men," International Journal of Sports Medicine, vol. 17, no. 6, pp. 397-403, 1996.

[43] K. Tsai, T. G. Hsu, K. M. Hsu et al., "Oxidative DNA damage in human peripheral leukocytes induced by massive aerobic exercise," Free Radical Biology \& Medicine, vol. 31, no. 11, pp. 1465-1472, 2001.

[44] A. Mastaloudis, T.-W. Yu, R. P. O'Donnell, B. Frei, R. H. Dashwood, and M. G. Traber, "Endurance exercise results in DNA damage as detected by the comet assay," Free Radical Biology \& Medicine, vol. 36, no. 8, pp. 966-975, 2004.

[45] A. Chaudhary, M. Nokubo, G. Reddy et al., "Detection of endogenous malondialdehyde-deoxyguanosine adducts in human liver," Science, vol. 265, no. 5178, pp. 1580-1582, 1994. 